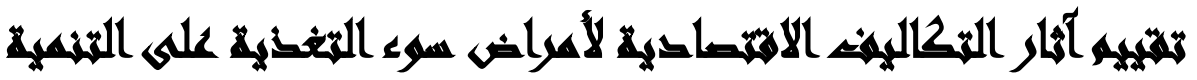 المستراهية هيمي هصر
}

$[r \cdot]$

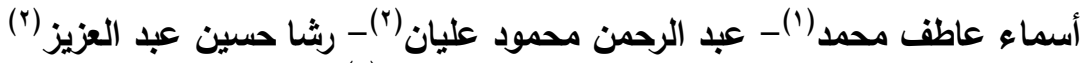

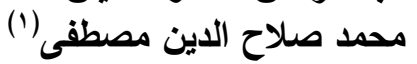

( ) كلية الدراسات العليا للطفوله، جامعة عين شمس ب) كلية التجارة، جامعة عين شمس المس

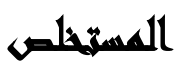

يهدف البحث إلى نقييم آثار التكاليف الاقتصادية لأمراض سوء التغذية؛ أحد أهم الإه

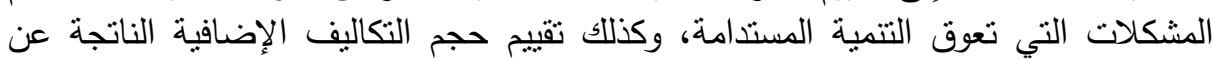



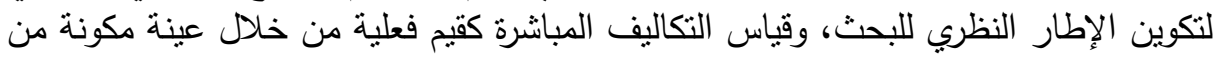

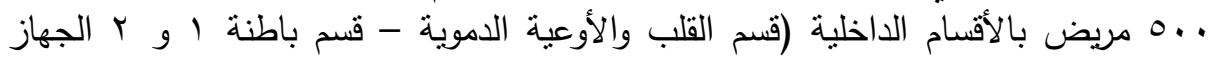

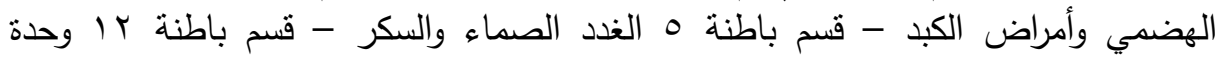

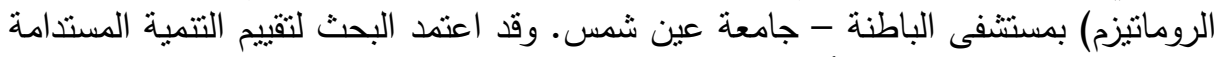

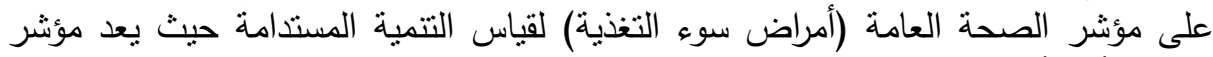

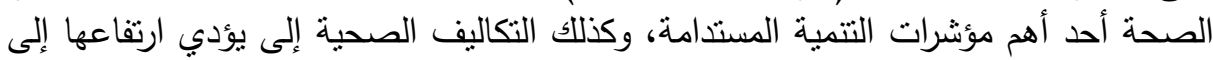

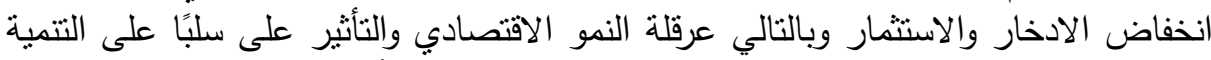

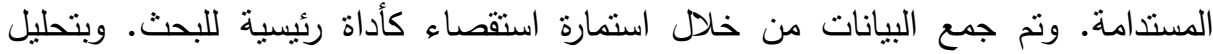

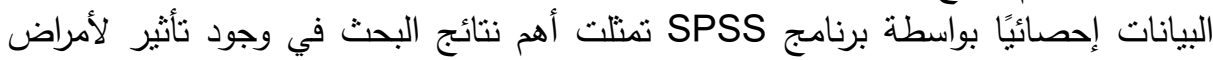

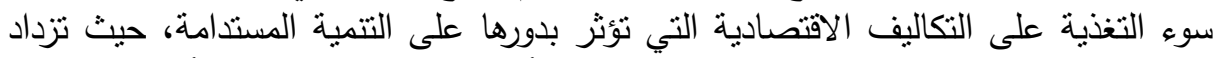

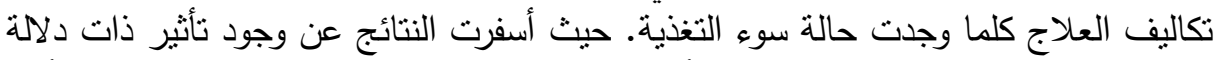

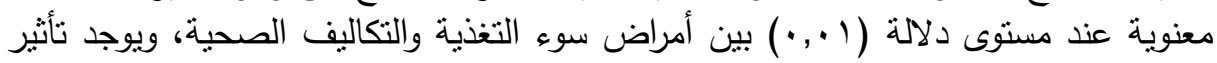

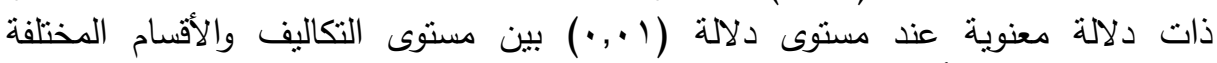

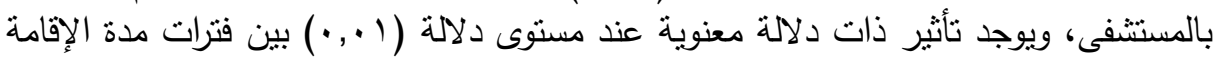

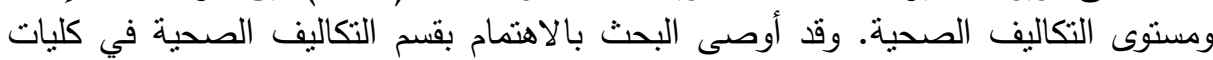
التجارة والاقتصاد في الجامعات المصرية، وكذللك الاعتماد على الاستنيان المستخدم في الإني

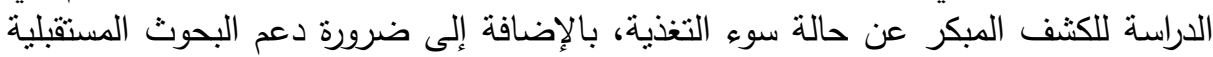

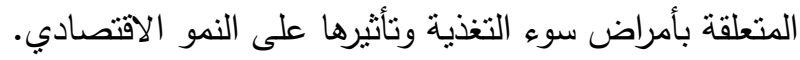




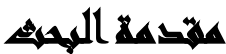

ظهرت في الآونة الأخيرة تغيرات سريعة على الأنظمة الغذائية وأساليب الحياة. ومع انتشار الأطعمة السريعة وعدم سلامة الأنظمة الغذائية في بعض الدول، وغياب الأمن الغذائي

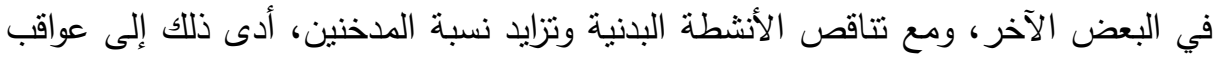
سلبية أثرت على صحة السكان وحالتهم الغذائية، مما قابل ذلك من أمراض مزمنة مرتبطة بالنظام الغذائي أي أمراض سوء التغذية. وتمنل هذه الأمراض أكبر عبء على الصحة العامة، وبالتالي تزداد الحاجة للوقاية منها. وقد يكون ذلك من خلال التوعية والتشجيع على التى

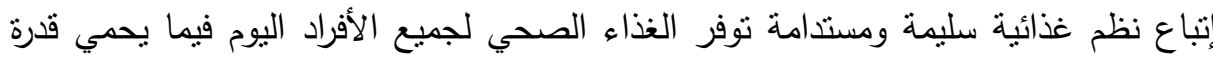
الأجيال القادمة على توفير الأغذية لنفسها.

وتؤدي سوء التغذية إلى الإصابة بالأمراض وتسبب ضعف عام أو عدم توازن في الطاقة والبروتين والعناصر الغذائية الأخرى، حيث تسبب مشاكل صحية كبيرة تعكس آثنارًا سلبية على لإنى المستويين المادي والمعنوي للمرضى، كما تقلل من القدرة على الاعتماد على النفس، وتسبب

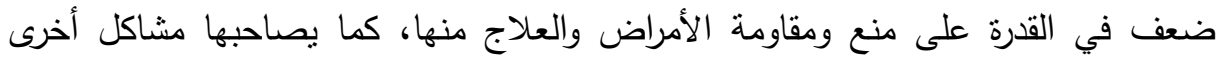

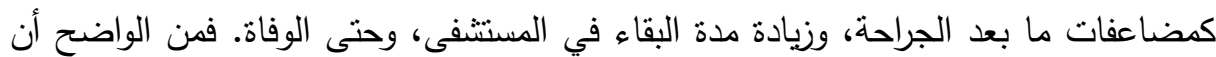
من الآتار المترتبة على علاج المرضى المصابون بسوء التغذية زيادة استنزاف موارد الرعاية

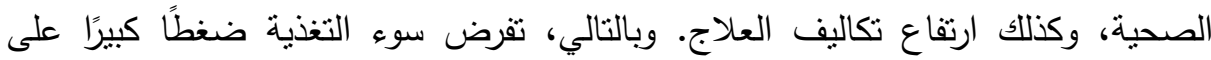
الاقتصاد ومصادر الرعاية الصحية والاجتماعية، كما تؤثز سلباً على المريض وعلى القائمين

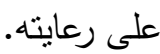

إن التتمية المستدامة والصحة العامة نربطهما علاقة وطيدة بحيث تؤثر إحداهما في

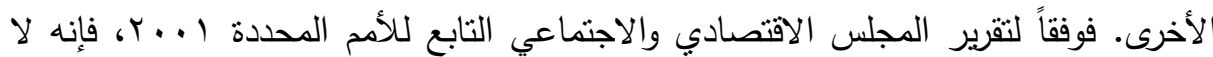

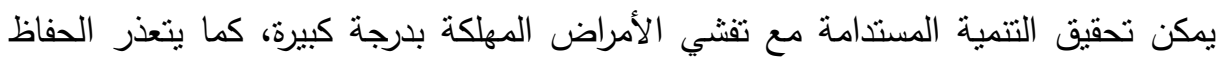

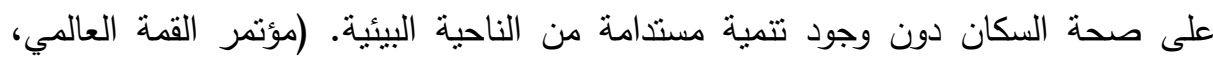

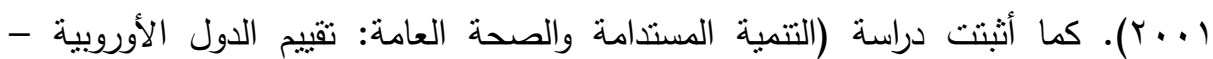

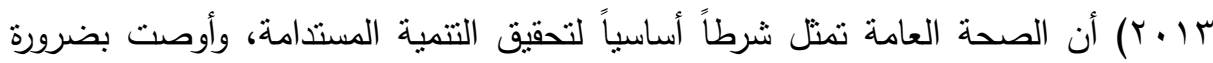


الاستتمار الدائم في الصحة والعمل على تحسينها. وكذللك أثتبت العديد من التقارير والدراسات أن الفوارق في المؤشرات بين الدول ما هي إلا انعكاسات للفوارق في التتمية الاقتصادية

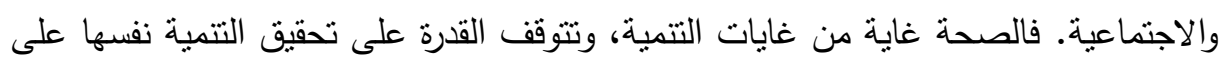

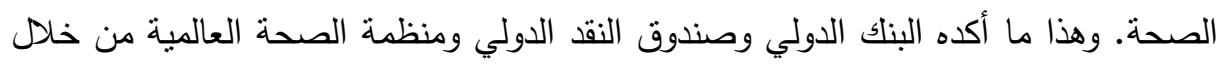
التشجيع على الاستثمار في رأس المال البشري عن طريق الصحة، واعنباره مطلبًا أساسيًا

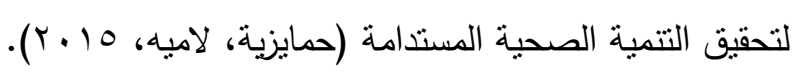
وعلاوة على ذلك، فلابد أن تعمل أنظمة الرعاية والصحة المستدامة من خلال الموائ، المارد الاجتماعية والبيئية المتاحة من أجل حماية وتحسين الأنظمة الصحية في الحاضر ولألجية ولفيال

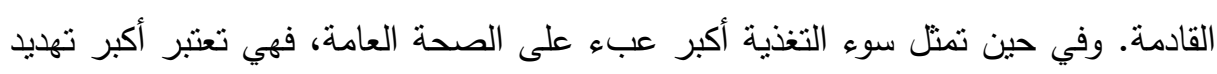
لتحقيق التتمية المستدامة، حيث تسبب في زيادة تكاليف العلاج وزيادة استهلاك الموارد

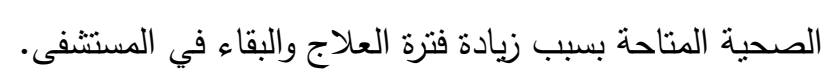

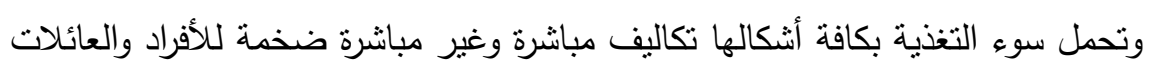

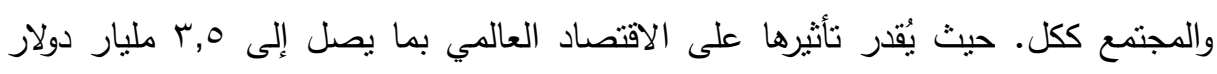

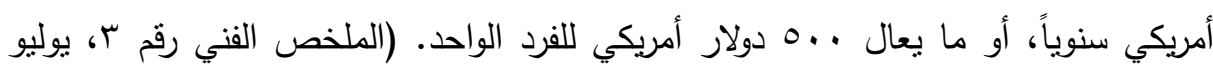
17 ا ـ - منظمة جلوبال بانل لأنظمة الغذاء والزراعة للتغذية).

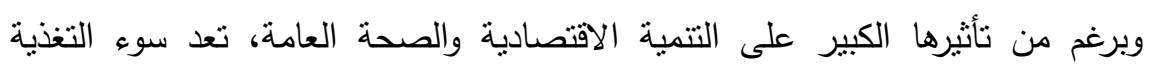

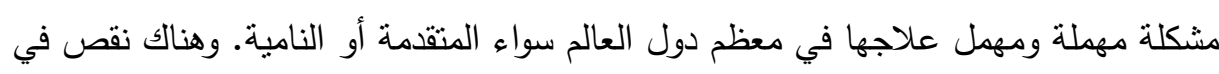
الدراسات العطلية حول كمية الأموال التي ممن المكن نوفيرها في حالة الفحص والدعم الغذائي. وافترحت بعض الدراسات أن الوقاية هي مفتاح التعامل مع مشكلة سوء التغذية. ولكن

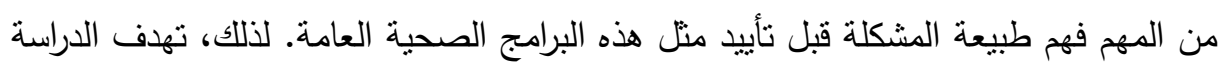
الحالية إلى فحص الموارد المستهكة والتكاليف المصاحبة لسوء التغذية في مصر وقياس آثار ذلك على التتمية المستدامة.

يقول الرئيس السابق لجمهورية غانا والرئيس التنفيذي لمنظمة بانال غلوبال "جون كوفور": "إن المكاسب الاقتصادية والاجتماعية الناتجة عن الاستثمار في التغذية هائلة

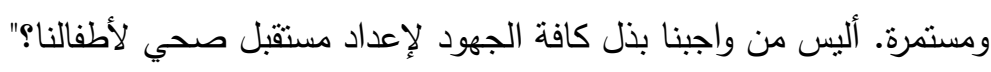

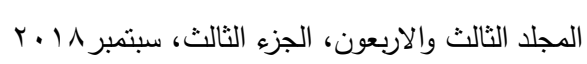




\section{And Ihan}

إن تكلفة أمراض سوء التغذية على الاقتصاد العالمي من حيث فقدان الإنتاجية وارتفاع

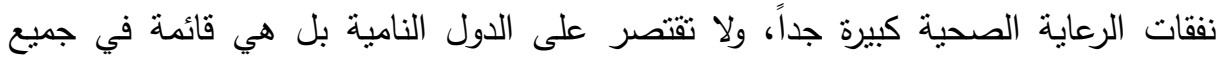

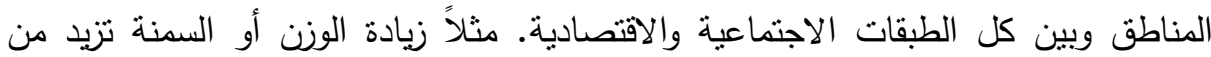
خطر الإصابة بمرض السكري من النوع الثاني، وارتفاع ضغط الدم، والسكتة الدماغية،


ويعاني الأفراد في سن العمل من الثقزم الناتج عن سوء التغذية خلال مرحلة الطفولة

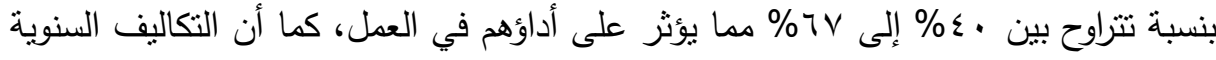

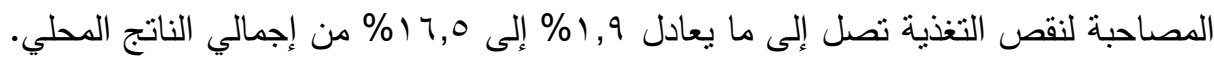
(الآثار الاقتصادية والاجتماعية لنقص تغذية الأطفال في مصر وأنثوبيا وسوازيلاند وأوغاندا"، برنامج الأغذية العالمي - الأمم المتحدة؛ اللجنة الاقتصادية لأفريقيا، 0 ( ب ب). كما تسبب سوء التغذية بكافة أنشكالها تكاليف مباشرة وغير مباشرة ضخمة للأفراد

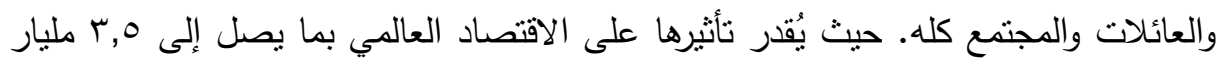

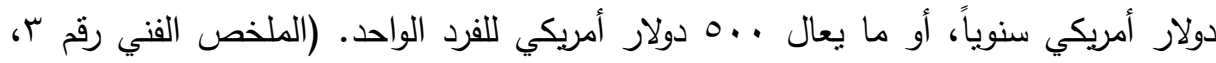

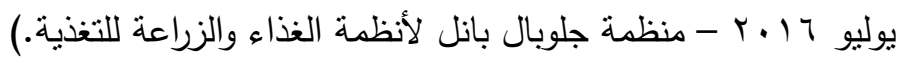

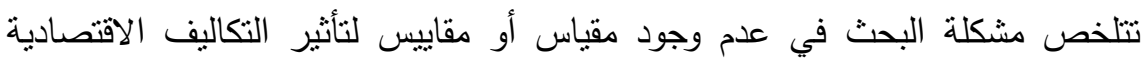
لأمراض سوء التغذية على التتمية المستدامة. وفي ضوء صياغة المشكلة أعلاه، يمكن تحديد هدف البحث في محاولة إجابة التساؤل التالي:

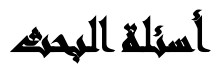

السؤال الرئيسي للبحث: ما إمكانية قياس تأثنر التكاليف الاقتصادية لأمراض سوء التغذية على التتمية المستدامة في مصر؟ كما يمكن الإجابة على السؤال الرئيسي من خلال الإجابة على الأسئلة الفرعية الآتية:-

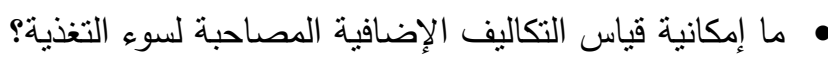


ما مدى تأثثر أمراض سوء التغذية على التتمية المستدامة؟

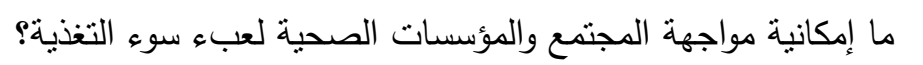

\section{أهسا اهخ المهيث}

وفي ضوء أهداف البحث المشار إليها، يمن تحقيق هذه الأهداف من خلال الخطوات

• • تركيز الانتباه على أحد المشكلات التي تعوق التتمية الاقتصادية.

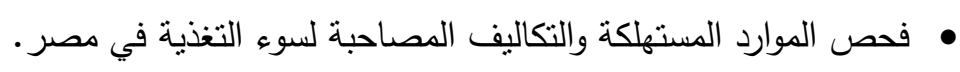

• ق قياس تكاليف العلاج الإضافية المصاحبة لسوء التغذية في مصر .

• ق قياس أثز التكاليف المصاحبة لسوء التغذية على التتمية المستدامة في مصر.

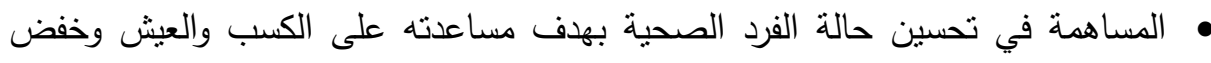

تكاليف العلاج، ومن ثم زيادة الدخل القومي والمساهمة في تحقيق التتمية المستدامة.

• استخلاص التجارب والرؤى المستقلية المقترح تتفيذها في مصر لمكافحة سوء التخذية.

\section{هروخ المهنه}

• هناك علاقة ذات دلالة معنوية بين تكاليف العلاج وحالة سوء التغذية (H1).

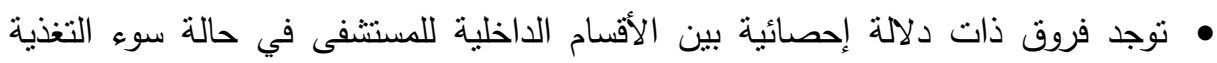

\section{متخغيراهت المهAه}

يبني البحث الحالي نموذجا يعبر عن التأثير المنطقي بين المتغير المستقل والمتغيرات التابعة حيث إن البحث يحتوي على متغير مستقل ومتغيرين تابعين حيث إن سوء التغذية هي المتغير المستقل والمتغير التابع الأول هو تكاليف العلاج والمتغير التابع الثاني هو التتمية المستدامة.

$$
\text { V1 }
$$$$
\text { V2 }
$$

V3: المتغيرات الديموغرافية (النوع/الحالة الاجتماعية/الحالة المهنية).

V4 


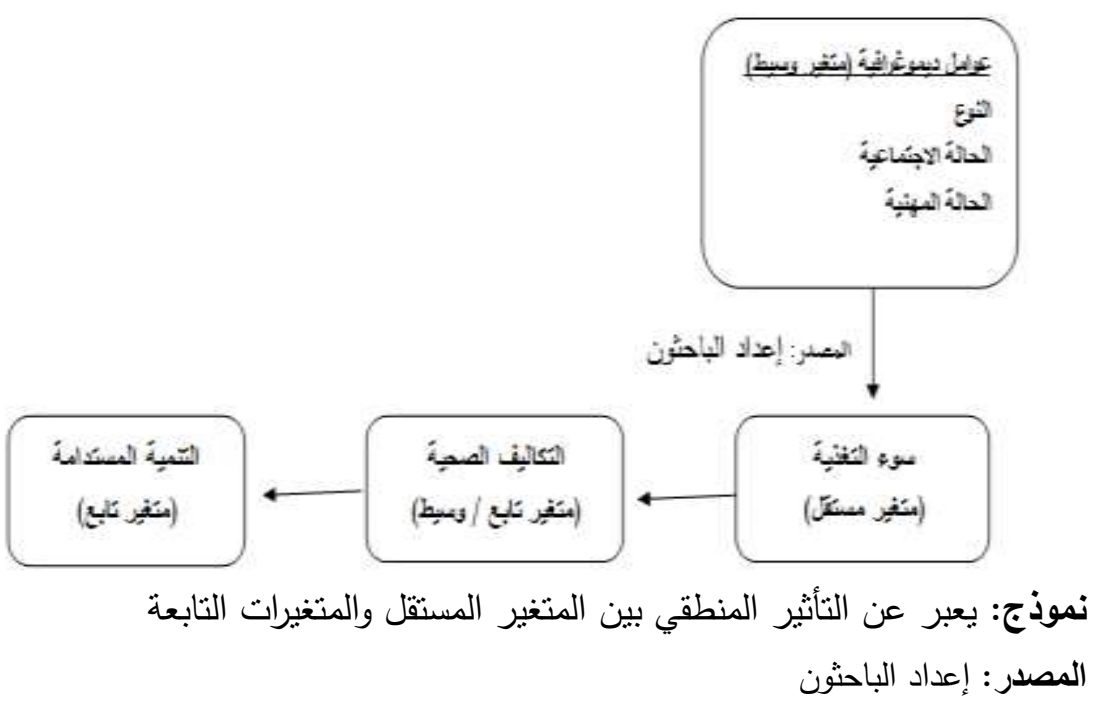

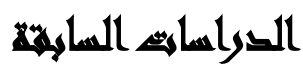

أولاً: الاراسات الأجنبية:

1) دراسة (الملخص الفني رقم ب "تكلفة سوء التغذية"، منظمة جلويال بانل لأنظمة الغذاء

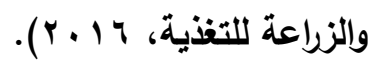

"The Cost of Malnutrition: Why Policy Action is Urgent?", Technical Breif No.3, Global Panel, 2016.

تكلفة سوء التغذية: لماذا تزداد الحاجة إلى التخخل السريع؟

الملخص الفني رقم بّ، يوليو 17 ـ ـ منظمة جلوبال بانل لأنظمة الغذاء والزراعة للتغذية.

يسعى المجتمع الدولي حالياً إلى تسريع وتعزيز خفض نسبة سوء التغذية في جميع أنحاء العالم. في هذا التقرير الفني جمعنا الأدلة التي تؤكد القيمة الاقتصادية لهذه الجهود العاجلة، لهئل ونؤكد على أنه لا توجد دولة تستطيع تحمل الخسارة الاقتصادية لمواطنيها بهذه الصورة الكبيرة

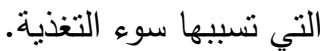
الملذص: تحمل سوء التغذية بكافة أثنكالها تكاليف مباشرة وغير مباشرة ضخمة للأفراد

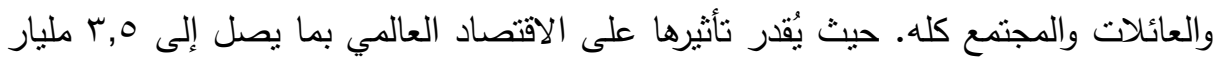


دولار أمريكي سنوياً، أو ما يعال . .0 دولار أمريكي للفرد الواحد. منل هذه التكاليف الباهظة

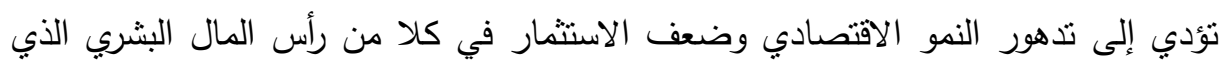

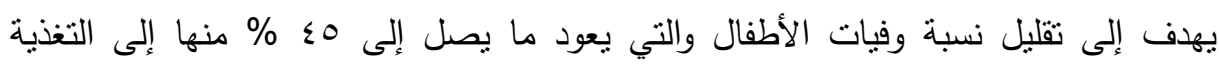
السيئة، ورأس المال البشري الذي يهدف إلى تقليل نسبة الوفيات من البالغين والمرنبطة بأنظمة غذائية متعلقة بالأمراض غير المعدية. كما أن هناك تكاليف إضافية نتتج عن تدهور القدرات

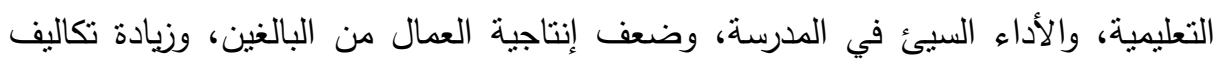

$$
\text { الرعاية الصحية. }
$$

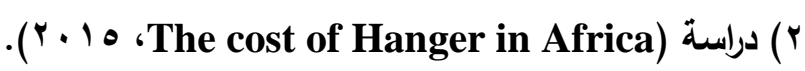

The Cost of Hanger in Africa:. "Social and Economic Impact of Child Under nutrition in Egypt, Ethiopia, Swaziland and Uganda, 2015.”

تكلفة الجوع في أفريقيا: الآثار الاقتصادية والاجتماعية لنقص تغذية الأطفال في مصر

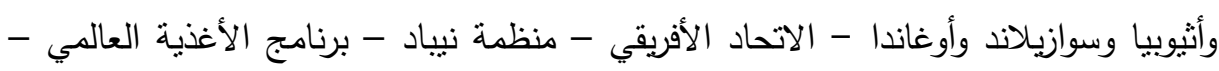
الأمم المتحدة؛ المفوضية الاقتصادية لأفريقيا 10 • r.

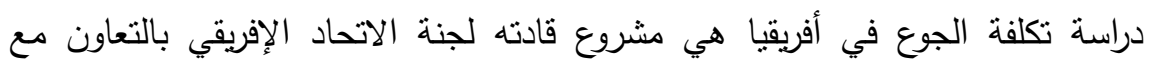

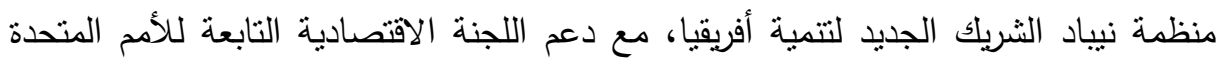

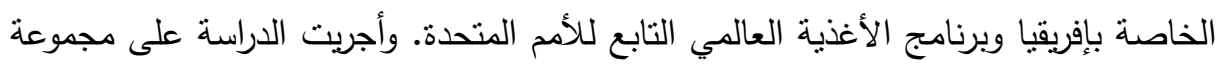
من الدول الإفريقية بهدف تقييم الآثار الاجتماعية والاقتصادية لنقص التغذية على الأطفال هناك. جمعت البيانات في هذه الدراسة من دول مصر وأثنوبيا وسوازيلاند وأوغندا. واستخلصت الاراسة نتائج مهمة منهيا:

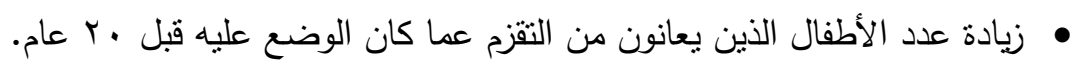

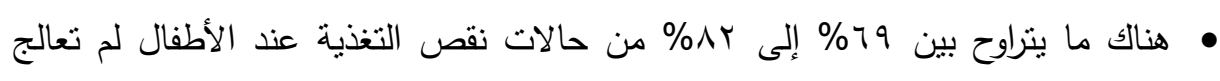
بطريقة مناسبة. • يخسر الأطفال الذين يعانون من التقزم ؟, • إلى Y, اسنة في التعليم المدرسي.

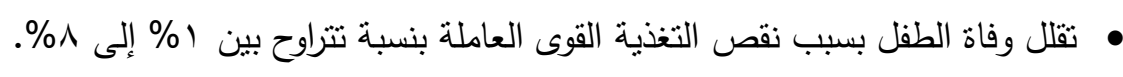

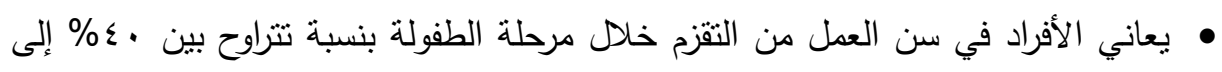
\% \%

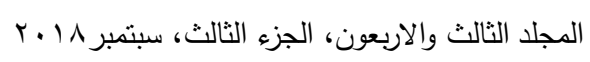


• التكاليف السنوية المصاحبة لنقص التغذية تصل إلى ما يعادل 9, (\% إلى 0,7 1\% من إجمالي الناتج المحلي. • القضاء على التقزم في إفريقيا يُعد خطوة هامة لتحقيق التتمية الثاملة في القارة.

r ب استة (Karen Freijer al, 2012).

"The economic costs of disease related malnutrition", Karen Freijer, Siok Swan Tan, Marc. Koopmanschap, Judith M.M. Meijers, Ruud J.G. Halfens, Mark J.C. Nuijten, Clinical Nutrition, 2012"

التكالبف الاقتصادبة لسوع التظذبة المرتبطة بالمرض.

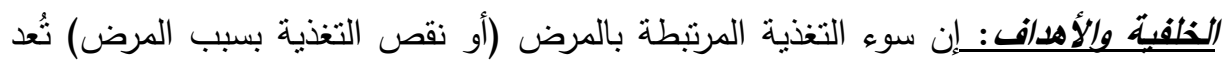

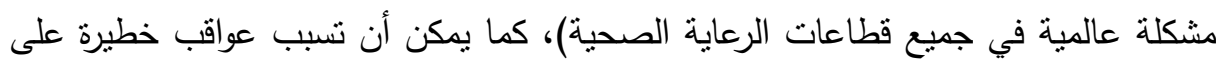

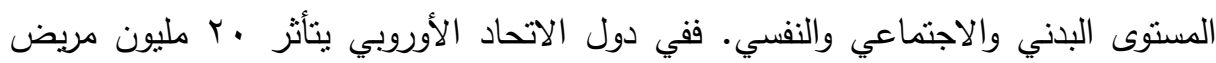

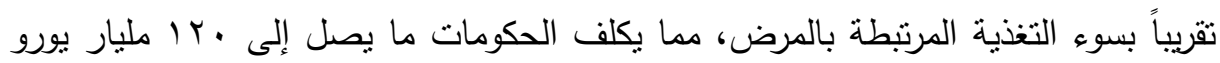
سنوياً. إن هدف هذه الدراسة هو تقدير التكاليف المضافة الإجمالية لسوء التغذية المرتبطة

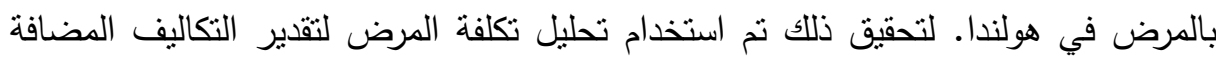

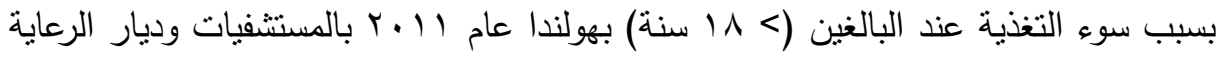
والتمريض وقطاعات الرعاية المنزلية، على أن ينم التعامل معها كقيمة نقدية مطلقة وكذلك بلك نسبة مئوية من إجمالي الإنفاق المحلي الهولندي على الصحة، ونسبة مئوية من إجمالي

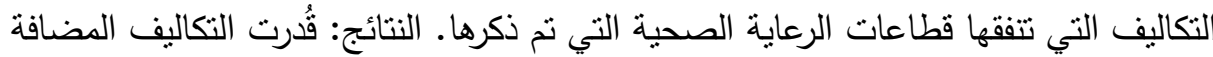
الإجمالية لعلاج المرضى البالغين الذين يعانون من سوء التغذية المرتبطة بالمرض بحوالي


و 9, § \% من إجمالي تكاليف قطاعات الرعاية الصحية التي تم التركيز عليها في الدراسة. 


\section{ثناتيًا: الدراسات والدوريات العربية}

أ. أل الدراسات

צ- دراسة (هدى سليمان محد إبراهيم، 10 ـ ب): أثر الرعاية المهنية على تنمية الموارد البشرية لتحقيق التنمية المستدامة، رسالة ماجستير، قسم العلوم الاقتصادية والقانونية

والإدارية البيئية، معهد الاراسات والبحوث البيئية.

المستخلص: يعتبر نظام التعاقب الوظيفي من أفضل الأنظمة العالمية لنطوير القيادات وهو

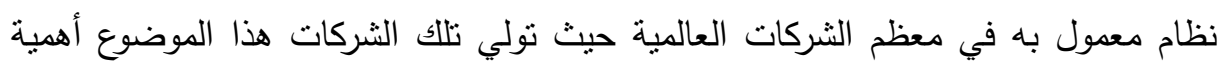
خاصة وتخصص الوقت والموارد الكافية لارتباط مستقبل الثركات بالقيادات المستقبلية، ويعد

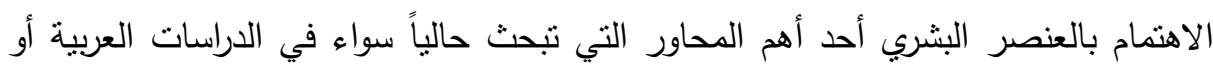
الأجنبية. ويعتبر موضوع تخطيط التعاقب الوظيفي أحد الموضوعات الهامة في مجال

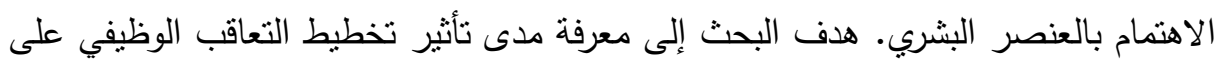

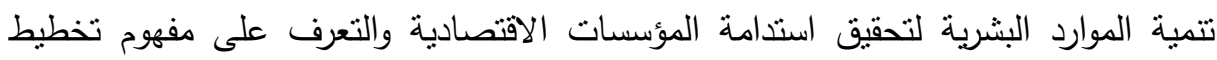
التعاقب الوظيفي وأهميته وعلاقته ببعض الدفاهيم الأخرى. وقد أسفرت النتائج إلى وجود تأثثر التير

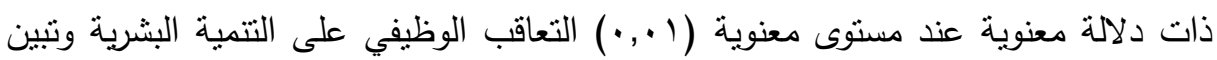
وجود تأثثر للتعاقب الوظيفي على لنتمية الموارد البشرية كما يوجد أنزر معنوي لنتمية الموارد البشرية على استدامة المؤسسات الاقتصادية.

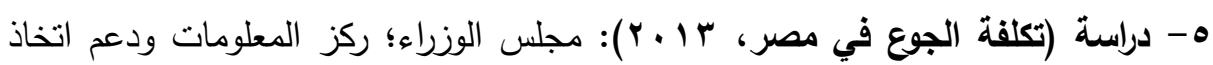

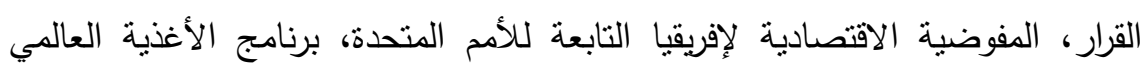

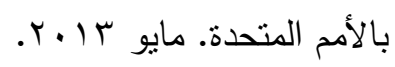

الملضص: تعرضت مصر خلال العقد السابق لسلسلة من الأزمات التي أدت إلى نراجع مالى مستوى الأمن الغذائي واتجاهات التغذية. وقد صاحب تزايد معدلات الفقر وانعدام الأمن

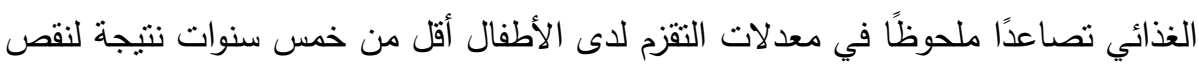

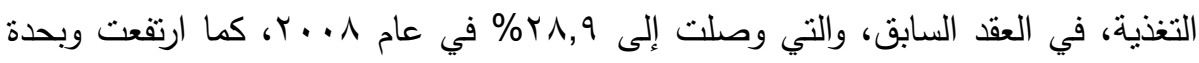

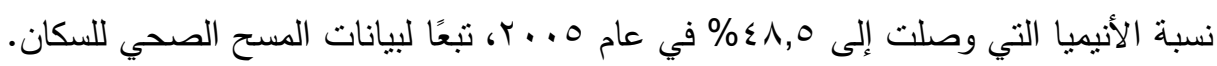

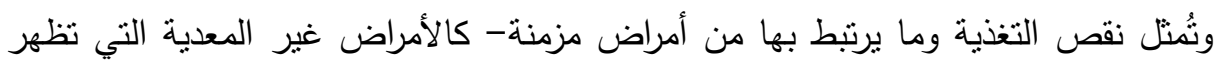

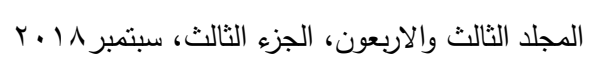


لاحقًا في حياة من يتعرضون لنقص التغذية في طفولتهم -تحديًا كبيرًا أمام صنع السياسات، في ظل الحلقة المفرغة من آثار نقص تغذية الأطفال.

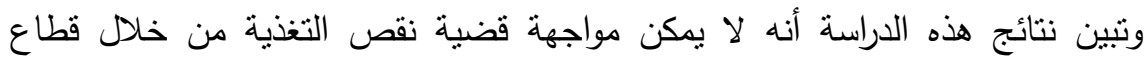
الصحة فقط، إنما من خلال تضافر كافة الجهود على المستوى الوطني، وذللك من خلال توجه هونه



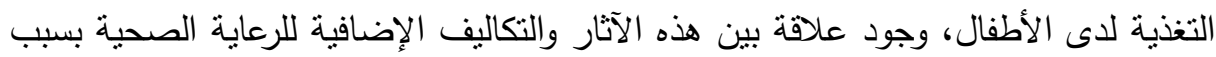

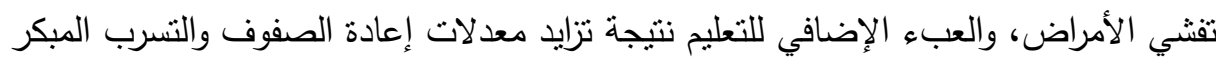

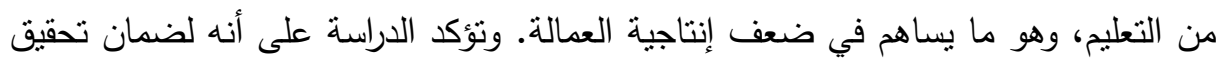
تتمية مستدامة على المدى البعيد فإنه لابد من مكافحة نقص التغذية والحد من تقزم الأطفال كأحد العناصر الرئيسية لأجندة التتمية الاجنماعية.

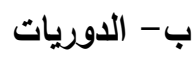

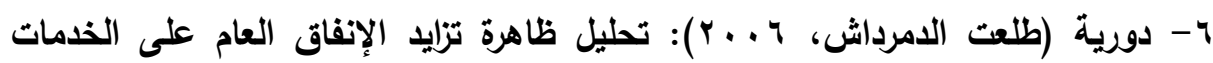

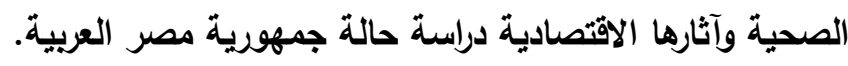

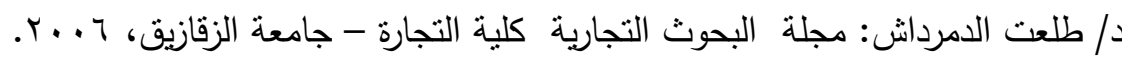

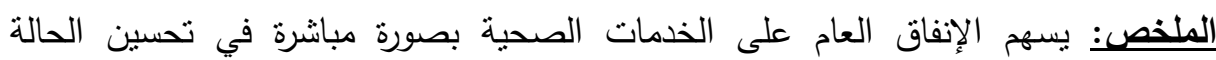
الصحية للفرد من خلال تقديم الخدمات الصحية العلاجية والخدمات الصحية الوقائية، بدون أن بتحمل مستهلكي تلك الخدمات لأية تكاليف مباشرة، أو يتحملون تكلفة مباشرة تقل كثيراً عن إجمالي تكلفة تللك الخدمات. وللإنفاق العام على الخدمات الصحية آثار انتشار خارجية موجبة Externalities، حيث يترتب استهلاك بعض أفراد المجتمع للخدمات الصحية العامة

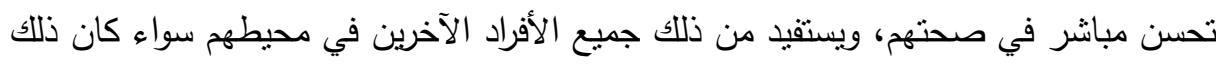

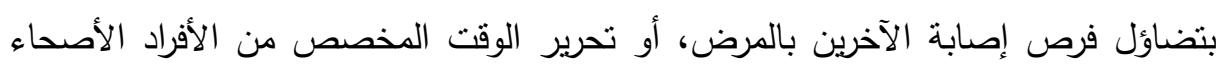
لرعاية المرضى، ليتحول إلى وقت منتج ومولد للاخل. 
ومن ثم يمكن تحليل الإنفاق العام على الخدمات الصحية في إطار أنه يعتبر أحد مكونات الإنفاق العام على الخدمات الصحية في إطار أنه يعتبر أحد مكونات الإنفاق العام

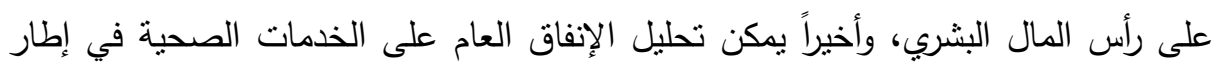
ضيق في حدود مكوناته ومحدداته.

ما بميز الاراسة الحالبة:

• تستهدف هذه الدراسة قياس تكاليف علاج الفئة الإنتاجية لأفراد المجتمع (1 ا - . وأثز سوء التغذية عليها.

• تحاول قياس معدل انتشار سوء التغذية بين المرضى على مستوى الأقسام الداخلية

بمستشفى الباطنة - جامعة عين شمس لمعرفة ددى تأثير ذلك على التتمية المستدامة.

• • توضيح مدى خطورة سوء التغذية على الصحة العامة.

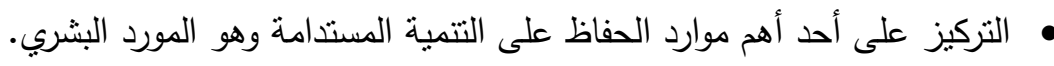

• تقييم العلاقة بين سوء التغذية وتكاليف العلاج والتتمية المستدامة.

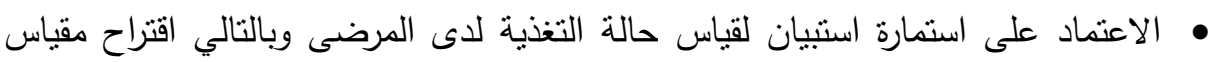

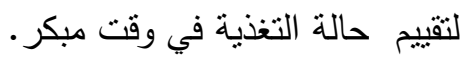

\section{الإطالر النظظيه}

مصطلحات البحث: مerms of study

( ) سـوء التغذيـة: Malnutrition: هي مشكلة صحية تشير إلى الاستهلاك غير

الكافي، أو الزائد أو غبر المنوازن من العناصر والمكونات الغذائية. وتسمى حالة عدم العيد

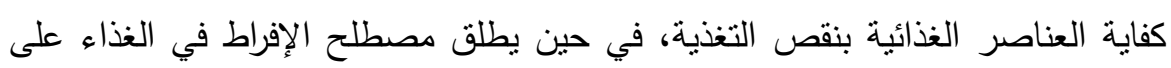

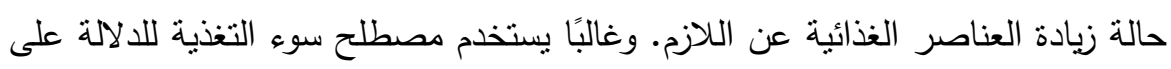

نقص التغذية، أي عدم كفاية السعرات والبروتين وغيرها. لو حدثت سوء التغذية للطفل

أثناء فترة الحمل أو في عمر أقل من سنتين، فقد تتسبب في مشاكل صحية مزمنة متعلقة

بنمو العقل والجسد. ويشمل مصطلح سوء التغذية ب مجموعات واسعة النطاق من الحالات

الصحية: (منظمة الصحة العالمية Who).

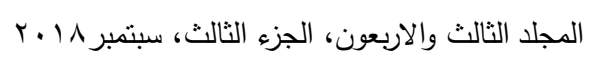


• نقص التغذية: الذي يشمل الهزال (انخفاض الوزن بالنسبة إلى الطول)، والتقزم (قصر القامة بالنسبة إلى العمر)، ونقص الوزن (انخفاض الوزن بالنسبة إلى العمر).

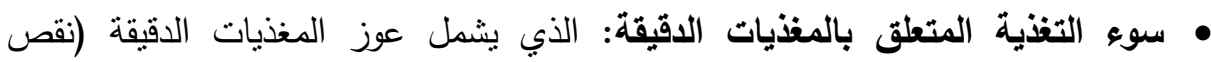
الفيتامينات والمعادن المهمة) أو فرط المغذيات الدقيقة. • فرط الوزن والسمنة والأمراض غير السارية المرتبطة بالنظام الغذائي (مثل أمراض القلب والسكتة الدماغية وداء السكري وبعض السرطانات). r) أمراض سوء التغذية: Diseases Related Malnutrition: ينتج عن سوء التغذية زيادة فرص العدوى، وبطيء التئام الجروح، وضعف قوة العضلات، وضعف أداء

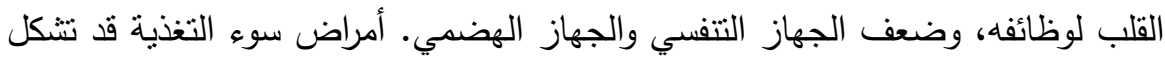
خطراً على الحياة. ب) التنميـة المستـامـة: Sustainable Development : هي عملية تطوير الأرض والمدن والمجتمعات وكذلك الأعمال التجارية بشرط أن تلبي احتياجات الحاضر بدون المساس بقدرة الأجيال القادمة على تلبية حاجاتها. ويواجه العالم خطورة التذهور البيئي الذي يجب التغلب عليه مع عدم التخلي عن حاجات التنمية الاقتصادية وكذلك المساواة والعدل الاجتماعي. التتمية الاقتصادية المستدامة هي التي تتضمن السياسات التي تكفل استمرار الأنشطة الاقتصادية بالمجتمع وأداء الدور المنتظر منها وفي نفس الوقت تكون

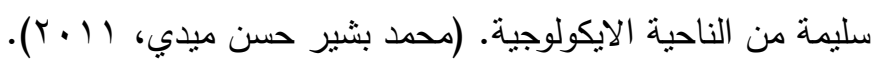
ع) التنمية الصحية المستدامة: Sustainable Health Development: تُعرف منية الصحة في دستور منظمة الصحة العالمية بأنها حالة اكتمال السلامة بدنياً وعقلياً ومهنياً

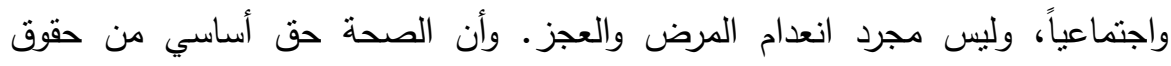

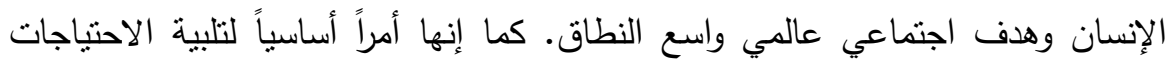

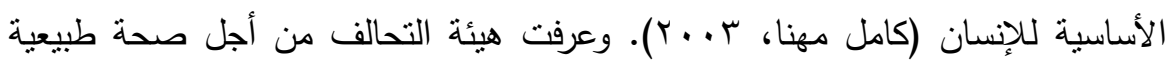

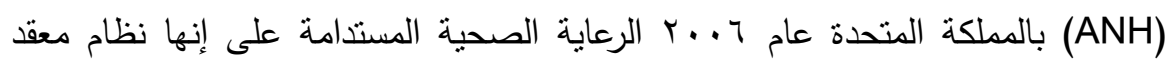
يتكون من عناصر مرتبطة تهدف إلى تجديد وإدارة وتعظيم جودة صحة الإنسان بالأخذ 
في الاعتبار العوامل البيئية. مع إمكانية نطبيق هذا النظام بيئياً واقتصادياً واجتماعياً إلى إلى

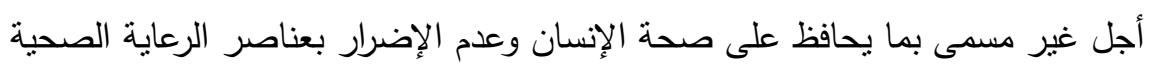

\section{إجراعايت التراسمة}

منهج البحث: سوف تعتمد الدراسة للتحقق من مدى صحة الفروض وتقييم أثر التكاليف

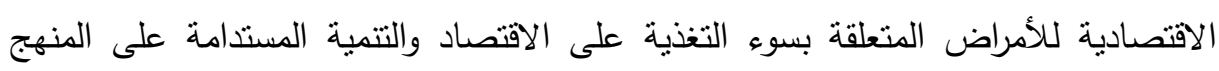
النظري من خلال التعرف على تجارب بعض الدول المنقدمة وكذلك الأبحاث والقراءات السابقة في مجال تقدير التكاليف الاقتصادية المصاحبة للأمراض المتعلقة بسوء التغذية وكيفية

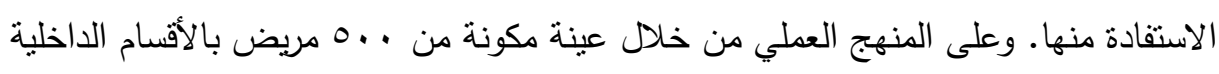
بمستشفى الباطنة - مستشفيات جامعة عين شمس. حدود البحث: تتمنل حدود البحث في الأتي:

• الحدود المكانية: الدول موضع البحث مصر ، مسنتفيات جامعة عين شمس - مسنتفى لآنى الباطنة.

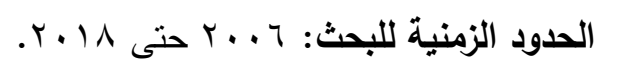
حيث اعتمد البحث على نتائج الدراسات السابقة في مجال نقدير تكاليف العلاج

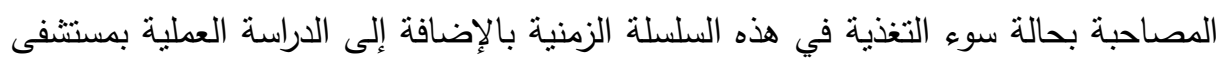


وتحقيق أهداف البحث.

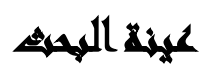

مجتمع البحث يتمنل في مرضى مستتفى الباطنة بمستشفيات جامعة عين شمس

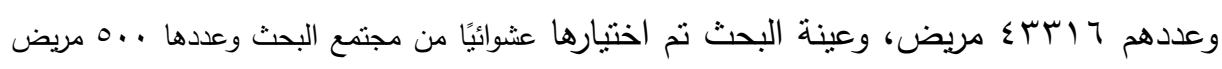

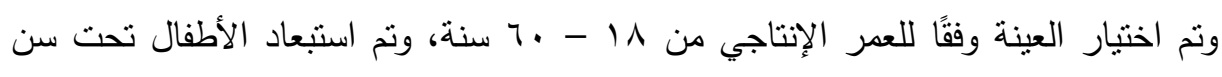

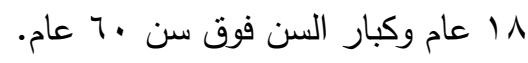




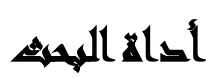

تم جمع البيانات عن طريق تصميم استمارة استبيان لتقيبم حالة التغذية مستشفى الباطنة

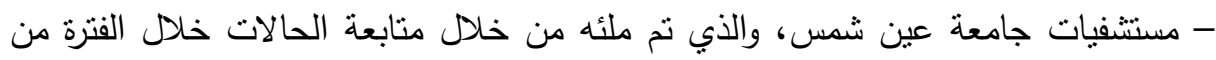

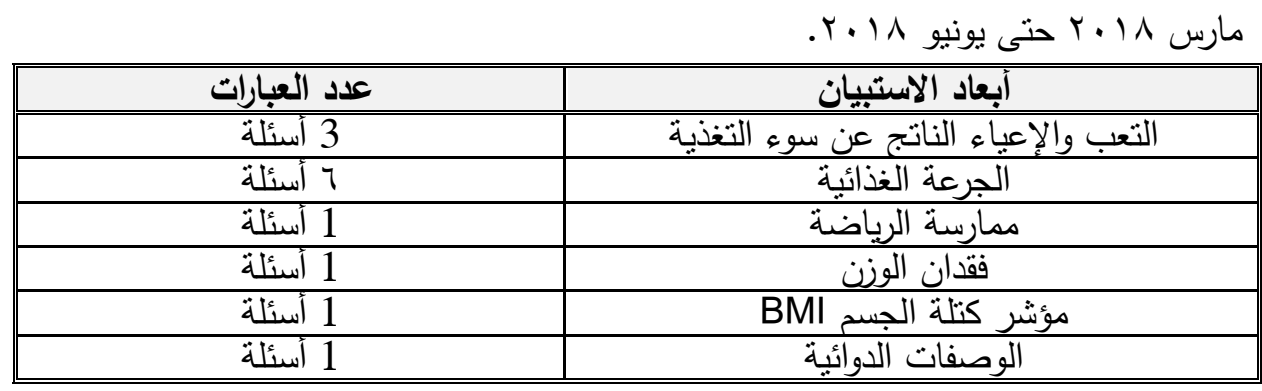
صدق وثبات استمارة الاستبيان

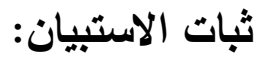

الثبات بطريقة ألفا كرونباخ: للتحقق من ثبات استبيان سوء التغذية لإمكانية الاعتماد على

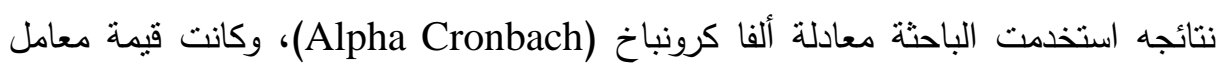

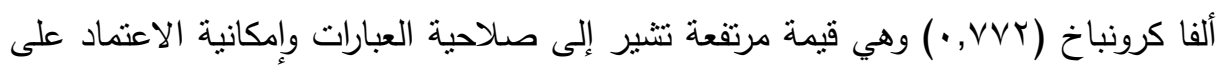
نتائجها والوثوق بها. الثبات بطريقة التجزئة النصفية: نم استخدام طريقة التجزئة النصفية للتأكد من ثبات الاستبيان

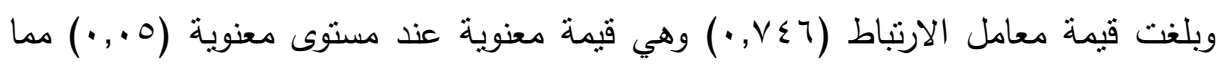

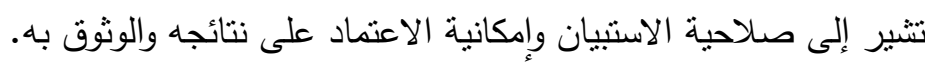

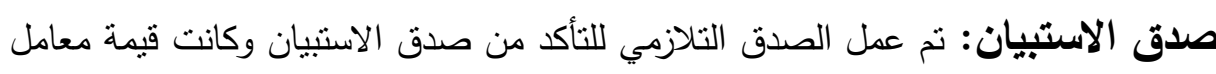

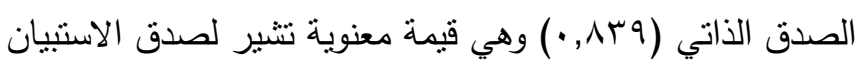




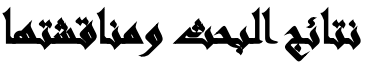

إختبار صحة الفروض: من خلال هذا الفصل عرضت الباحثة نتائج الدراسة بعنوان "تقييم آثار التكاليف الاقتصادية لأمراض سوء التغذية على التتمية المستدامة في مصر" ونم تحليل

$$
\text { البيانات في ضوء فروض الدراسة. ووجدت الآتي: }
$$

1- اختبار صحة الفرض الأول: ينص الفرض الأول على: هناك علاقة ذات دلالة معنوية

بين حالة سوء التغذية وتكاليف العلاج (H1). ويوضح الجدول الآتي هذه العلاقة:

جدول(1/1): اختبار كاب لنوضيح الفروق بين مستوى التكاليف (المنخفض - المتوسط -

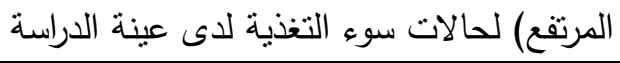

\begin{tabular}{|c|c|c|c|c|c|c|c|c|c|}
\hline \multirow[b]{2}{*}{ الالالة } & \multirow[b]{2}{*}{$\tau^{د}$} & \multirow[b]{2}{*}{ SL } & \multirow[b]{2}{*}{ معامل الاتباط } & \multirow[b]{2}{*}{ الإجمالي } & \multicolumn{3}{|c|}{ حالة التغذية } & & \multirow[b]{2}{*}{ مستوى } \\
\hline & & & & & سوء تغذية & خطر سوء & تغذية طبيعية & & \\
\hline \multirow{8}{*}{.033} & \multirow{8}{*}{4} & \multirow{8}{*}{$\begin{array}{c}10.509 \\
\mathrm{a}\end{array}$} & \multirow{8}{*}{0.44} & 155 & 46 & 106 & 3 & العدد & \multirow{2}{*}{ منذ } \\
\hline & & & & $31.00 \%$ & $26.10 \%$ & $33.30 \%$ & $50.00 \%$ & النسبة & \\
\hline & & & & 178 & 57 & 118 & 3 & العدد & \multirow{2}{*}{ متوسط } \\
\hline & & & & $35.60 \%$ & $32.40 \%$ & $37.10 \%$ & $50.00 \%$ & النسبة & \\
\hline & & & & 167 & 73 & 94 & 0 & العدد & \multirow{2}{*}{ مرثنع } \\
\hline & & & & $33.40 \%$ & $41.50 \%$ & $29.60 \%$ & $0.00 \%$ & النسبة & \\
\hline & & & & 500 & 176 & 318 & 6 & العدد & \multirow{2}{*}{ الإجمالي } \\
\hline & & & & $100.00 \%$ & $100.00 \%$ & $100.00 \%$ & $100.00 \%$ & النسبة & \\
\hline
\end{tabular}

يتضح من الجدول السابق وجود فروق دالة إحصائياً بين مستوى التكاليف (المنخفض -

المتوسط - المرتفع) في حالات سوء التغذية لاى عينة الدراسة حيث بلغت قيمة (كابن)



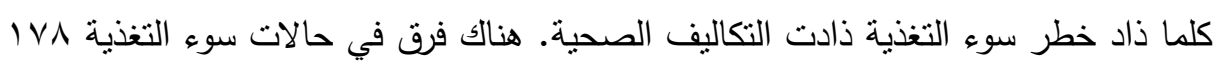
- 100 = 100



\begin{tabular}{|c|c|c|c|c|}
\hline الخطأ المعياري للقيم & معامل التحديد & $\begin{array}{l}\text { معامل التحديد } \\
\text { (R2) }\end{array}$ & $\begin{array}{c}\text { الارتباط (R) } \\
\text { (R) }\end{array}$ & النموذج \\
\hline 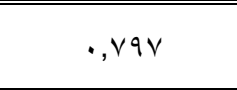 &., 10 & $\cdot, I V$ & • & مؤشر سوء التغذية وأثثره على \\
\hline
\end{tabular}


يتضح من الجدول السابق لتحليل الانحدار الخطي البسيط أن قيمة معامل الارتباط (R)

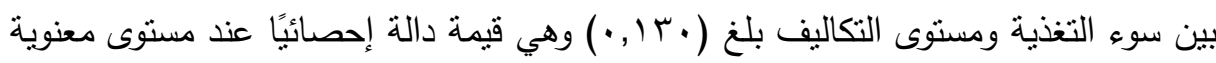

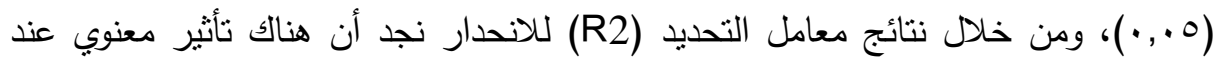

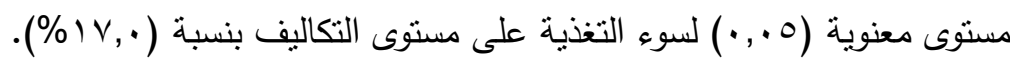
جدول(1/1): تحليل التباين ANOVA لنموذج الانحدار لدراسة العلاقة بين سوء التغذية

\begin{tabular}{|c|c|c|c|c|c|}
\hline المعنتوية & قيمة ف & المربعات & الدرجاتة & المربعموع & لتموذج \\
\hline$\cdot, \cdots \varepsilon$ & $\Lambda, 01 \mathrm{~V}$ & $\begin{array}{l}0,5.9 \\
.7+0\end{array}$ & $\begin{array}{c}1 \\
\leqslant 91 \\
\leqslant 99\end{array}$ & 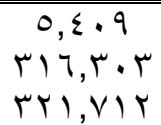 & الإلبواقي \\
\hline
\end{tabular}

وباختبار معنوية نموذج الانحدار بالاعتماد على قيمة (ف) التي بلغت (^,0)V بمستوى معنوية (ع . , •) مما يؤكد على معنوية نموذج الانحدار.

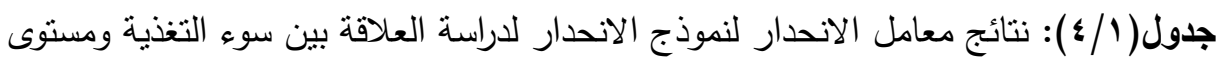

\begin{tabular}{|c|c|c|c|c|c|c|}
\hline \multirow{2}{*}{ مسنتوى } & \multirow{2}{*}{ قيمة t } & معاملات معيارية & \multicolumn{2}{|c|}{ معاملات غير معيارية } & \multirow{2}{*}{\multicolumn{2}{|c|}{ النموذج }} \\
\hline & & بيتا & الخطأ المعياري & قيمة B & & \\
\hline $\begin{array}{l},, \ldots \\
,, \ldots \leqslant\end{array}$ & $\begin{array}{l}\curlywedge, q \vee \curlyvee \\
r, q) \wedge\end{array}$ & • & $\begin{array}{l}\cdot,|V| \\
., \text { OVY }\end{array}$ & $\begin{array}{l}1,047 \\
., Y .9\end{array}$ & سوء التغذية (مستقل) & 1 \\
\hline
\end{tabular}

تم من خلال النموذج اختبار معنوية معامل الانحدار (B) والذي يوضح وجود علاقة

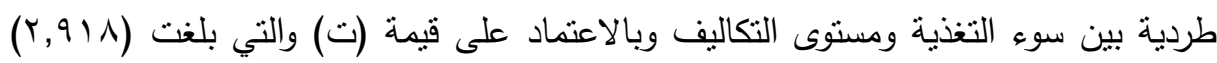
بمستوى معنوية (ع . ., •) مما يظهر معنوية معامل الانحدار (B). مما سبق بتضح صحة الفرض الأول: هناك علاقة ذات دلالة معنوية بين حالة سوء التغذية وتكاليف العلاج. 
r- اختبار صحة الفرض الثاني: ينص الفرض الثاني على: نوجد فروق ذات دلالة إحصائية

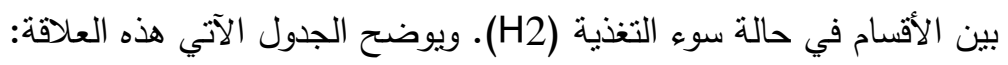
جدول(r/Y): اختبار ف ANOVA لتوضيح الفروق بين الأقسام في حالة سوء التغذية التية

\begin{tabular}{|c|c|c|c|c|c|}
\hline 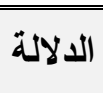 & ف & الالمعياري & المتوسط & العدد & القسم \\
\hline \multirow{6}{*}{$\cdot, \cdots$} & \multirow{6}{*}{$\Lambda, \Gamma \div)$} &., $0 Y 9$ & r,ro & $1 \ldots$ & القلب والأوعية الدموية \\
\hline & & $\cdot, \varepsilon 7 \mu$ & $Y, Y T$ & $1 \cdots$ & باطنة ا الجهاز الهضدى وأمراض الكبد \\
\hline & & $\cdot, \leqslant 7 \mu$ & $Y, Y T$ & $1 \cdots$ & باطنة r الجهاز الهضدى وأمراض الكبد \\
\hline & & $\cdot, \varepsilon 0 \wedge$ & T,YO & $1 \ldots$ & باطنة ه الغدد الصماء والسكر داخلى \\
\hline & & $\cdot, \sum 97$ & $T, 0 \Lambda$ & $1 \ldots$ & باطنة r با وحدة الروماتيزم \\
\hline & & $\cdot, \leqslant 99$ & $r, r \leqslant$ & $0 \ldots$ & الإجمال \\
\hline
\end{tabular}

يتبين من الجدول السابق للفروق بين الأقسام في حالة سوء التغذية وجود فروق دالة

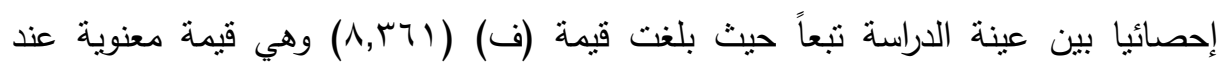

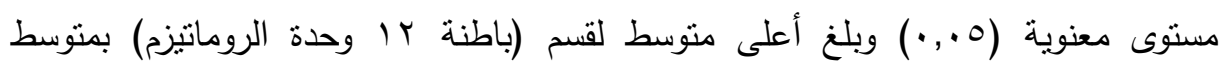

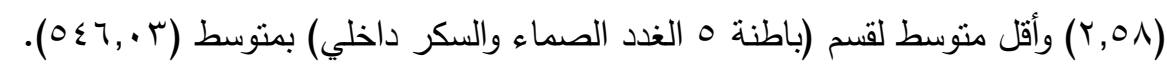
جدول(r/r): اختبار كاب لتوضيح الفروق بين الأقسام في حالة سوء التغذية

\begin{tabular}{|c|c|c|c|c|c|c|c|c|}
\hline \multirow[b]{2}{*}{ الدلالة } & \multirow[b]{2}{*}{ د } & \multirow[b]{2}{*}{ كاץ } & \multirow[b]{2}{*}{ الإجمالي } & \multicolumn{3}{|c|}{ سوء تغذية } & & \multirow[b]{2}{*}{ القسم } \\
\hline & & & & سوء تغذية & خطز سوء & طغيية & & \\
\hline \multirow{12}{*}{$\cdot, \ldots 1$} & \multirow{12}{*}{$\wedge$} & \multirow{12}{*}{ r } & $1 \ldots$ & rA & 09 & $r$ & العدد & \multirow{2}{*}{ القلب والأوعية } \\
\hline & & & $\% 1 \ldots, \ldots$ & $\%$ \% , . & $\% \circ 9, \ldots$ & $\% r, \ldots$ & النسبة & \\
\hline & & & $1 \ldots$ & $r V$ & $V Y$ & 1 & العدد & \multirow{2}{*}{ الهضاطنة ألجي وأمراض الكبد } \\
\hline & & & $\% 1, \ldots,$. & $\% r \vee, \ldots$ & $\% \vee r, \ldots$ & $\% 1, \ldots$ & النسبة & \\
\hline & & & $1 \ldots$ & rV & VY & 1 & العدد & \multirow{2}{*}{ الهضاطنة ب الجهاز } \\
\hline & & & $\% 1, \ldots, \ldots$ & $\% r \vee, .$. & $\% \vee r, \ldots$ & $\% 1, \ldots$ & النسبة & \\
\hline & & & $1 \ldots$ & ry & $v r$ & 1 & العدد & \multirow{2}{*}{ الصاطنة ه الغدد } \\
\hline & & & $\% 1, \ldots, \ldots$ & $\%$ \%ч, . & $\% \vee r, .$. & $\% 1, \ldots$ & النسبة & \\
\hline & & & $1 \ldots$ & 01 & $\leq r$ & . & العدد & \multirow{2}{*}{ باطنة r ا الروحدة } \\
\hline & & & $\% 1, \ldots, \ldots$ & $\% \circ \wedge, \ldots$ & $\% \varepsilon r, .$. & $\% \cdot, \ldots$ & النسبة & \\
\hline & & & $0 .$. & 187 & TIA & 7 & العدد & \multirow{2}{*}{ الإجمالي } \\
\hline & & & $\% 1 \ldots, \ldots$ & $\%$ \% , r. & \%чr, . & $\% 1, r$. & النسبة & \\
\hline
\end{tabular}


يتضح من الجدول أنه توجد فروق ذات دلالة إحصائية بين الأقسام في حالة سوء

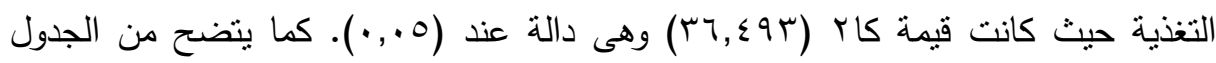
أيضًا (بالنسبة لكل قسم على حده) أن أعلى نسبة لخطر سوء التغذية قسم باطنة ه الغدد

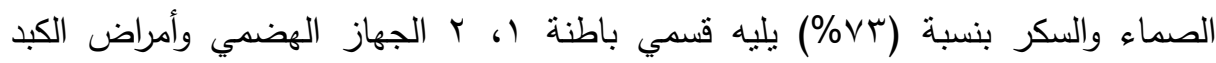

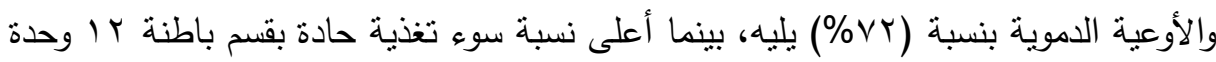

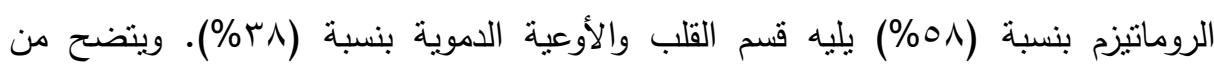
الجدول أيضًا (جميع الأقسام) أن معدل انتشار سوء التغذية في الأقسام عال حيث وصله لرعل إجمالي نسبة المعرضين لخطر سوء التغذية (؟,r؟\%\%) من إجمالي حجم العينة، والمصابين

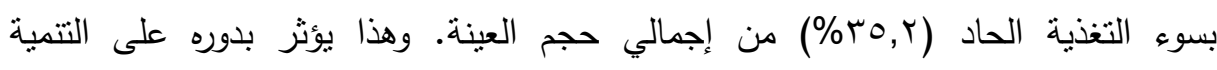
المستدامة حيث يؤدي ضعف أداء العاملين بسبب المرض إلى انخفاض إنتاجيتهم. مما سبق يتضح صحة الفرض الخامس: نوجد فروق ذات دلالة إحصائية بين الأقسام في حالة سوء التغذية.

\section{نئائي السراسلة}

هناك علاقة طردية موجبة بين حالة سوء التغذية وتكاليف العلاج أي أن تكاليف العلاج

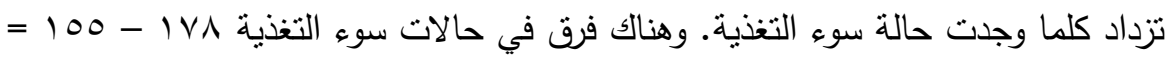

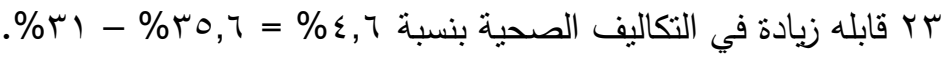



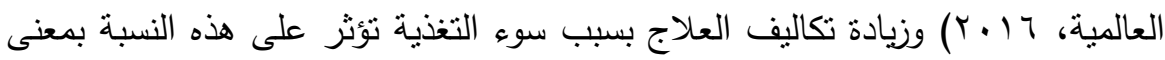

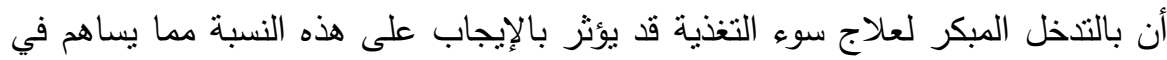
تحسين التتمية المستدامة. معدل انتشار سوء التغذية في الأقسام عال حيث وصل إجمالي نسبة المعرضين لخطر

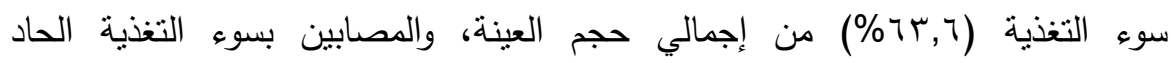

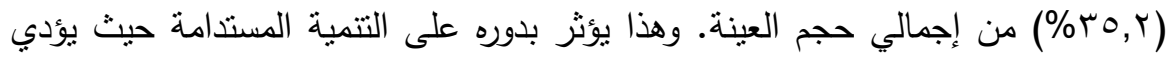
ضعف أداء العاملين بسبب المرض إنمالى إلى انخفاض إنتاجيتهم. 


\section{المئزوياند}

> ضرورة الاهتمام بقسم التكاليف الصحية في كليات التجارة والاقتصاد في الجامعات

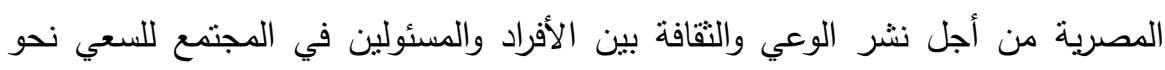
تحقيق مستوى صحي عال مع المحافظة قدر الإمكان على الموارد الصحية وتخفيض الحن تكاليف العلاج، الأمر الذي يؤثر بدوره إيجابيًا على التتمية المستدامة.


التغذية خاصًا بين الأطفال حيث تؤثر سوء التغذية عليهم في مراحل التحصيل الدراسي فئي وقوتهم البدنية في سن العمل مما يؤثر سلبًا على إنتاجيتهم.

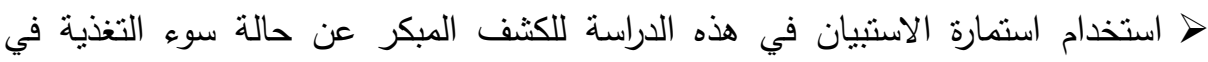
المسنتفيات لما قد يكون له من تأثثير كبير في تخفيض تكاليف العلاج ومعدل انتشار

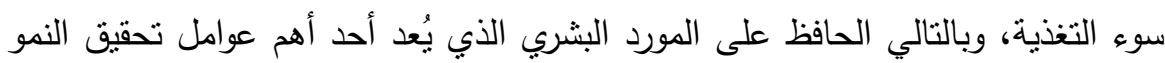
والحفاظ على التتمية المستدامة. > دعم البحوث المستقبلية المتعلقة بتكاليف العلاج المصحوبة بسوء التغذية ودراسة مدى ولى فاعلية التذخل المبكر وأثزه على تخفيض تكاليف العلاج وتوفير صحة أفضل لأفراد |

\section{anll}

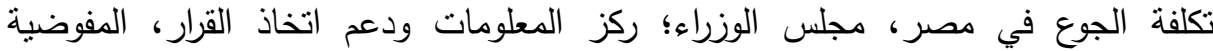

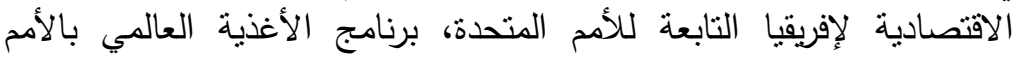

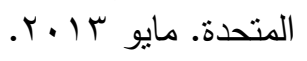

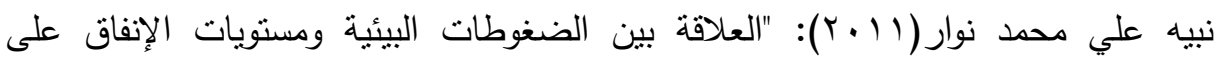
المرض" رسالة ماجستير، قسم العلوم الاقتصادية والقانونية والإدارية البيئية،

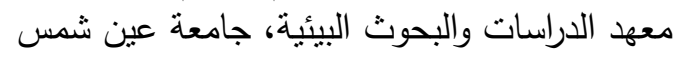

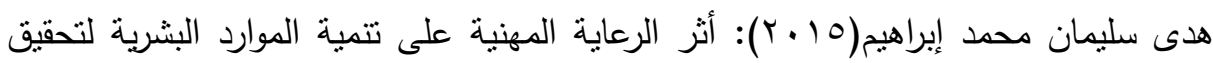

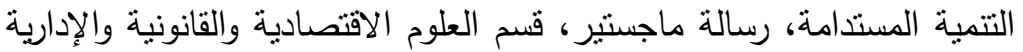
البيئية، معهد الدراسات والبحوث البئية البئية

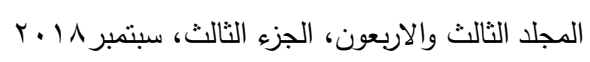


البرنامج الإنمائي للأمم المتحدة(ץ . ب): "الأهداف التتموية للألفية في البلدان العربية"، نيويورك

تقرير شنجن فان - مدير عام المعهد الدولي لبحوث السباسات الغذائية، أكتوبر عـ ـ ؟. تقرير البنك الدولي - الأهداف الإنمائية للألفية - القضاء على الفقر الددقع والجوع بحلول

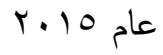

تقرير الأمين العام للأمم المتحدة: "الصحة والمرض والوفيات والتتمية"، الأمم المتحدة، المجلس

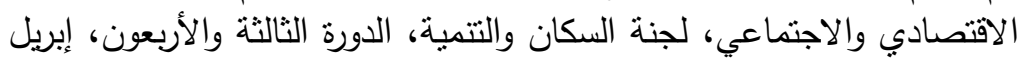

دورية طلعت الدمرداش: "تحليل ظاهرة الإنفاق العام على الخدمات الصحية وآثارها الاقتصادية: دراسة حالة جمهورية مصر العربية"، مجلة العانة البحوث التجارية،

دورية علمية نصف سنوية، كلية التجارة، جامعة الزقازيق، العدد الثاني، الجزية التئه

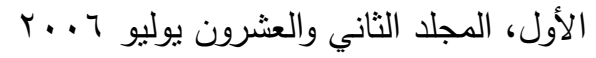

ألفت درويش( 997 ( ): الكتاب الطبي الجامعي "الغذاء والتغذية"، منظمة الصحة العالمية.

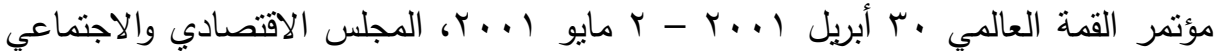

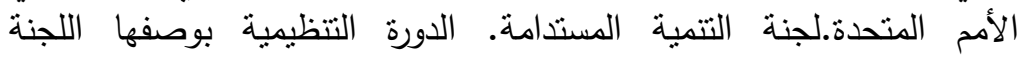
التحضيرية لمؤتمر القمة العالمي المعني بالتئمية المستدامة

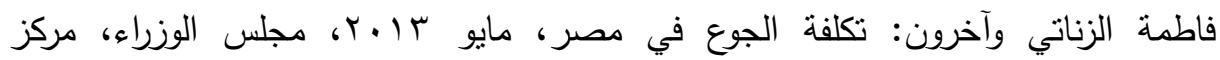

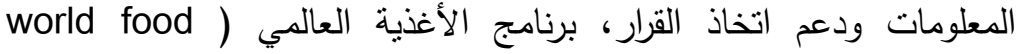
.(program "WFP"

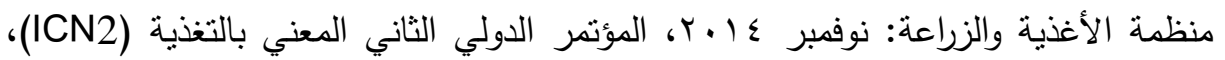
مقالة "تغذية أفضل تعني حياة أفضل

Karen Freijer, (2012): The economic costs of disease related malnutrition, Clinical Nutrition.

R. J. Stratton, (2012): Clinical and economic effects of managing malnutrition, Institute of Human Nutrition. School of Medicine. University of Southampton. UK..

The Cost of Malnutrition: Why Policy Action is Urgent. Technical brief No.3, Global Panel, July 2016.

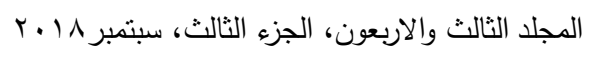


The Cost of HUNGER, Social and Economic Impact of Child Undernutrition in Egypt, Ethiopia, Swaziland and Uganda, united nation, 2015. TEC

\title{
EVALUATION IMPACT OF THE ECONOMIC COSTS OF MALNUTRITION DISEASES OF EGYPT'S SUSTAINABLE DEVELOPMENT
}

Mohamed, Asmaa, A. ${ }^{(1)}$; Alian, A. M. ${ }^{(2)}$; Abdel Aziz, Rasha, H. ${ }^{(2)}$ and Mostafa, M. S. ${ }^{(1)}$

1) Faculty of Postgraduate Childhood Studies, Ain Shams University.

2) Faculty of Commerce, Ain Shams University.

\begin{abstract}
The study aims to refer to one of the major problems that impedes sustainable development, as well as to clarify the additional costs resulting from malnutrition and the extent to which it affects economic growth. The analytical descriptive approach was used to form the theoretical framework of the study. The study also measures the direct costs of malnutrition as actual values through a sample of 500 patients at Al Batinah Hospital - Ain Shams University. For evaluating sustainable development, the researcher used Public Health Index (Malnutrition Diseases) as health indicator is one of sustainable development measures, and high health costs which cause limited saving and investment which, in turn, negatively affects economic growth. The researcher collected data through a questionnaire form as a major research tool. Then data were analyzed statistically by SPSS. The research results show the impact of malnutrition on economic costs that, in turn, affect sustainable development, the study found a significant effect between diseases accompanied with malnutrition and health costs, a significant effect between the level of costs and malnutrition in the different sections of the hospital and a significant effect Between
\end{abstract}

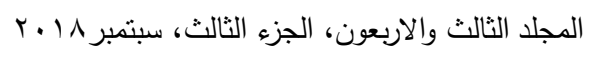


مجلة العلوم البيئية

معهد الدراسات والبحوث البيئية - جامعة عين شمس لئه

periods of stay in the hospital and health costs. The researchers recommend that a development of the department of health costs in the faculties of commerce and economics at Egyptian universities should be considered, as well as the use of the current study's questionnaire for early detection of malnutrition and, finally, the study recommends supporting future studies related to malnutrition diseases and their impact on the economy. 